\title{
Systemic treatment and radiotherapy, breast cancer subtypes, and survival after long-term clinical follow-up
}

\author{
Sherry X. Yang ${ }^{1}$ (D) Eric C. Polley ${ }^{2}$
}

Received: 20 October 2018 / Accepted: 21 January 2019 / Published online: 12 February 2019

(c) The Author(s) 2019

\begin{abstract}
Background It remains unclear whether breast cancer subtypes are associated with clinical outcome in patients without any treatment including systemic and radiation therapy as an independent entity. Understanding the survival profiles among subtypes by treatment status could impact optimal selection of treatments.

Methods Patients were diagnosed with invasive breast cancer from the community hospitals across four geographical regions of the United States. Expression of hormone receptor (HR) and HER2 in tumor specimens from 1169 patients was centrally determined by immunohistochemistry and fluorescence in situ; breast cancer was classified into $\mathrm{HR}^{+} / \mathrm{HER}^{-}, \mathrm{HR}^{+} /$ $\mathrm{HER}^{+}{ }^{+}$, triple-negative, and HER $2^{+}$subtypes. Overall survival (OS) at a median follow-up of about 15 years among subtypes in untreated patients and those with systemic treatments and radiotherapy was analyzed by Kaplan-Meier method and multivariable analysis adjusting for age, tumor size and grade, number of positive nodes, stage and breast cancer subtypes. Results Without treatment, breast cancer subtypes were not associated with OS $(P=0.983)$ and remained insignificant for prognosis by multivariable analysis after adjusting for confounders. This contrasted with a significant survival difference across the subtypes in patients with conventional therapies $(P<0.0001)$. Compared with $\mathrm{HR}^{+} / \mathrm{HER}^{-}$subtype, triple-negative subtype (HR 1.5, 95\% CI 1.11-2.04; $P=0.009$ ) and HER2 ${ }^{+}$subtype (HR 2.18, 95\% CI 1.48-3.28; $P=0.0001$ ) were significantly associated with worse survival by multivariable analyses.

Conclusion Breast cancer subtypes are not associated with survival in untreated patient population and, in contrast, significantly associated with prognosis in patients with conventional therapy. The data provide evidence of treatment-associated differential outcomes among breast cancer subtypes.
\end{abstract}

Keywords Breast cancer subtypes $\cdot$ Hormone receptor $($ HR) $\cdot$ HER2 $\cdot$ Overall survival $\cdot$ Radiotherapy $\cdot$ Systemic treatment $\cdot$ Triple-negative breast cancer

\section{Abbreviations}

CI Confidence interval

ER Estrogen receptor

HR Hormone receptor; hazard ratio

HER2 Human epidermal growth factor receptor-2

Electronic supplementary material The online version of this article (https://doi.org/10.1007/s10549-019-05142-x) contains supplementary material, which is available to authorized users.

Sherry X. Yang

Sherry.Yang@nih.gov

1 Division of Cancer Treatment and Diagnosis, National Cancer Institute, National Institutes of Health, Bethesda, MD, USA

2 Division of Biomedical Statistics and Informatics, Department of Health Sciences Research, Mayo Clinic, Rochester, MN, USA
PR Progesterone receptor

TNBC Triple-negative breast cancer

OS Overall survival

\section{Background}

Breast cancer accounts for about a quarter of all cancers and $15 \%$ of cancer-specific deaths in women globally [1]. It is the most frequently diagnosed and second leading cause of cancer mortality for women in the United States, with about 260,000 new incidences and approximate 40,000 deaths recorded each year [2]. About $13-41 \%$ of patients with operable stage I, II and III breast cancer experience distant and local relapses, and eventually succumb to their disease [3, 4]. Hormone receptor (HR) and human epidermal growth factor receptor 2 (HER2) are integrated into clinical 
management and lately prognostic staging of breast cancer [5-7]. HR (estrogen receptor $\alpha, \mathrm{ER}^{+}$and/or progesterone receptor, $\mathrm{PR}^{+}$)-positive breast cancer is consisted of $65-80 \%$ of all breast cancers, which are routinely managed by 5 years of endocrine therapy that is extended up to 10 years in recent years [8-10]. Patients with high risk factors such as HER2positivity $\left(\mathrm{HER} 2^{+}\right)$, HR-negative $\left(\mathrm{HR}^{-}\right)$status or positive lymph nodes are recommended for cytotoxic chemotherapy $[8,11]$. Radiation therapy is recommended for all patients who undergo breast cancer conserving surgery and may be used for those either with a cancer larger than $5 \mathrm{~cm}$ or nodepositive disease after mastectomy.

The intrinsic gene expression signatures in breast cancer were discovered by DNA microarray technology that classifies breast cancer into the molecular subtypes predominantly as luminal A, luminal B, HER2-enriched and basal-like [12]. Largely in agreement with the gene expression profiling data, breast cancer is categorized into $\mathrm{HR}^{+}$/ $\mathrm{HER}^{-}{ }^{-}\left(\mathrm{ER}^{+}, \mathrm{PR}^{+}\right.$and $\mathrm{HER} 2^{-}$or luminal-A), $\mathrm{HR}^{+} / \mathrm{HER}^{+}{ }^{+}$ $\left(\mathrm{ER}^{+}, \mathrm{PR}^{+}\right.$and HER2 ${ }^{+}$or luminal-B), HER2 ${ }^{+}\left(\mathrm{HER} 2^{+}\right.$, $\mathrm{ER}^{-}$and $\mathrm{PR}^{-}$or HER2-enriched), and triple-negative breast cancer (TNBC or $\mathrm{ER}^{-}, \mathrm{PR}^{-}$and HER2 ${ }^{-}$or basal-like) subtypes by established immunohistochemistry (IHC) classifier [13]. The IHC-based classification with joint HR and HER2 status is the mostly implemented method for establishing breast cancer subtypes in the clinic [14]. The molecular subtypes were found to provide prognostic information, with luminal subtypes exhibiting better clinical outcomes [15, 16]. The St. Gallen expert consensus panel has adopted a subtype-based approach in the context of current treatment modalities of early stage breast cancer [17]. However, some studies revealed that intrinsic subtyping was not prognostic nor predictive of response to treatments [18]. In a large cohort study, there was no significant difference in survival according to molecular subtype 5 years after diagnosis until $\sim 20$ years of clinical follow-up [19]. The gene expression signature established from most of the patients receiving radiotherapy and conventional therapy cannot predict outcomes of untreated patients [20,21].

Currently, it remains unclear whether the molecular subtype has prognostic significance in patients who did not undergo any type of therapy including systemic treatments and radiation therapy except surgery. Thus, there is a heightened need to evaluate outcome by subtype in women with and without multimodality therapy within a population separately. In this investigation, our study objectives are the overall survivals (OS) by treatment status among breast cancer subtypes using Kaplan-Meier and multivariable Cox regression analyses adjusting for confounding factors.

\section{Methods}

\section{Patient population and breast cancer subtypes}

The study patient population was consisted of women diagnosed with invasive breast cancer with stage I, II or III from 1985 to 1997 in the community hospitals of four geographical regions of the United States as described previously $[22,23]$. They participated in the accreditation program of the Commission on Cancer of the American College of Surgeons. The project received full review and approval by institutional review board at each participating site [22]. The coded dataset established was centrally maintained, which includes age, clinical and pathological variables, types of treatment received, vital status, and clinical follow-up for a maximum of 282 months (23.5 years) [22]. All 1169 patients represented by the Cooperative Breast Cancer Tissue Resource (CBCTR), but one, underwent surgery for primary treatment of their disease. This resulted in 1168 participants including 372 patients who did not receive treatments, and 796 with endocrine therapy, chemotherapy and radiation therapy alone, and/or in combination. No patients received trastuzumab treatment in the population.

Breast cancer subtypes were determined by HR status including ER and PR, and HER2 status, which were centrally assayed and scored by the CBCTR pathologists according to the American Society of Clinical Oncology (ASCO) and the College of American Pathologists (CAP) guidelines [24, 25]. ER/PR was assessed as positive if $\geq 1$ tumor cells stained. HER 2 positivity was defined as IHC Score $3+$, IHC Score $1+$ or $2+$ or IHC not available and FISH amplified. The four major breast cancer subtypes defined by immunohistochemistry and fluorescence in situ hybridization (FISH) were $\mathrm{HR}^{+} / \mathrm{HER} 2^{-}$and $\mathrm{HR}^{+} / \mathrm{HER}^{+}$ subtypes; HER $2^{+}$subtype was defined as having HER $2^{+}$ and $\mathrm{HR}^{-}$status; and triple-negative breast cancer was referred to the tumors with all three markers being negative (TNBC; $\mathrm{HER} 2^{-} / \mathrm{ER}^{-} / \mathrm{PR}^{-}$). Of 1168 patients, 16\% were unclassified due to a lack of ER/PR and HER2 data and were excluded for clinical outcome analysis. This study on the de-identified human tumor specimen/dataset was received approval from the Office of Human Research Protections, National Institutes of Health (Bethesda, Maryland). The study complies with the REMARK reporting recommendations for tumor marker studies [26].

\section{Statistical analysis}

Chi-squared test of association was used to compare categorical variables among breast cancer subtypes by 
treatment status. Length of follow-up for OS was defined as number of months from the date of diagnosis to the date of death due to any cause, or to the date last known alive. Assessment of time to survival event interval used the Kaplan-Meier method and the log-rank test for association. Cox's proportional hazards method was used for multivariable models including age at diagnosis, year of diagnosis, histology type, tumor size and grade, and number of positive nodes, TNM stage, and/or breast cancer subtypes. A $P$ value less than 0.05 was considered statistically significant. All statistical analysie were performed in R (R Foundation).

\section{Results}

\section{Patient and clinicopathologic factors, and breast cancer subtypes by treatment status}

Of 1169 participants, 986 (84\%) were successfully classified into the breast cancer subtypes by the established IHC/ FISH classifier. The median age of 986 participants was 60 years (range 25 to 96 years). There were 301 patients who did not receive any treatment, and 685 that received either endocrine therapy (164 patients), chemotherapy (138 patients), and radiation therapy (94 patients) alone or in combination (289 patients). Table 1 summarized the distribution of demographic and clinicopathologic characteristics by subtype in the untreated patients. More women with $\mathrm{HR}^{+}$/ HER $^{-}{ }^{-}(83 \%)$ and HER2 ${ }^{+}(84.6 \%)$ tumors were older than 50 years relative to those with triple-negative $(67.4 \%)$ and $\mathrm{HR}^{+} / \mathrm{HER} 2^{+}(66.7 \%)$ subtypes $(P=0.047)$. TNBC subtype had $67.4 \%$ and HER $2^{+}$category had $69.2 \%$ of grade III tumors, in contrast to $12.9 \%$ for $\mathrm{HR}^{+} / \mathrm{HER} 2^{-}$and $28.6 \%$ for $\mathrm{HR}^{+} / \mathrm{HER} 2^{+}$subtypes $(P<0.001)$. At diagnosis, about $46 \%$ of HER $2^{+}$subtype had positive lymph node status, compared to $\sim 15 \%$ for $\mathrm{HR}^{+} / \mathrm{HER} 2^{-}, \sim 24 \%$ for $\mathrm{HR}^{+} / \mathrm{HER} 2^{+}$, and $\sim 23 \%$ for TNBC subtypes $(P=0.025)$.

Within the patient population receiving conventional treatments, the distribution of age and clinicopathologic variables by subtype were shown in the Supplementary Table 1. There was a significant variation of tumor sizes or $\mathrm{T}$ stage among subtypes. The age, tumor grade, and number of positive nodes remain significantly different across the subtypes as the untreated patient group.

\section{Survival by subtype with and without treatments}

The median follow-up for OS was 177 months or 14.75 years (range of 1 to 282 months or 0.08 to 23.5 years) in the patient population. We evaluated the association between breast cancer subtypes and prognosis separately by treatment status through both univariate and multivariable analyses (Fig. 1; Tables 2, 3).

In untreated patients, OS rates were similar among $\mathrm{HR}^{+} / \mathrm{HER}^{2}{ }^{-}, \mathrm{HR}^{+} / \mathrm{HER}_{2}{ }^{+}, \mathrm{TNBC}$, and HER2 ${ }^{+}$subtypes by Kaplan-Meier estimate of the probability (logrank $P=0.983$; Fig. 1a). The survival curves overlapped during the entire follow-up time of up to 23.5 years. By contrast, there was a significant association between OS and the subtypes in patients with treatments (log-rank $P<0.0001$; Fig. 1b). As expected, women with $\mathrm{HR}^{+} /$ HER2 ${ }^{-}$subtype had best survival, followed by those with $\mathrm{HR}^{+} / \mathrm{HER} 2^{+}$, TNBC and HER $2^{+}$subtypes. Noticeably, survival decreased precipitately within the first 5 years for TNBC and HER2 ${ }^{+}$subtypes, with the decline slowing down during the subsequent 5 years. The difference in OS among subtypes diminished after 10 years and, thereafter, converged, suggesting that the effect of systemic and/or radiation therapy gradually weakened or disappeared.

\section{Survival by subtype with and without treatments by multivariable analyses}

We next evaluated OS for patients in the no-treatment group using multivariable Cox proportional hazards regression model. It was comprised of prognostic factors including not only age at diagnosis, tumor characteristics, number of positive lymph nodes and stage but also the molecular subtypes as covariates (Table 2). As compared with $\mathrm{HR}^{+} / \mathrm{HER}^{-}$subtype, adjusted hazard ratio (HR) was 1.1 for $\mathrm{HR}^{+} / \mathrm{HER}^{+}{ }^{+}$subtype $(95 \%$ CI $0.55-2.07$; $P=0.781), 0.62$ for HER $2^{+}(95 \%$ CI $0.29-1.58 ; P=0.273)$ and 0.67 for TNBC (95\% CI $0.40-1.18 ; P=0.158)$ subtypes. Noticeably, survival outcomes of patients with HER2 ${ }^{+}$and TNBC subtypes were not inferior to the $\mathrm{HR}^{+} /$ HER2 ${ }^{-}$subtype. The risk of breast cancer mortality was 2.2-fold greater for women with age more than 50 years (95\% CI 1.35-3.64; $P=0.0017$ ), and 1.1 for the number of positive nodes (95\% CI 1.04-1.18; $P=0.00074$ ). Thus, age and number of positive nodes, rather than breast cancer subtypes, were independent prognostic indicators for unfavorable outcomes in patients who did not receive radiation and systemic therapy.

In women with treatments, HER2 ${ }^{+}$(adjusted HR 2.18; 95\% CI 1.46 to $3.28 ; P=0.0001)$ and TNBC $(1.5 ; 95 \% \mathrm{CI}$ 1.11 to $2.04 ; P=0.0091$ ) subtypes were significantly associated with the decreased survival by multivariable analysis adjusting for age, tumor size and grade, number of positive nodes, stage and breast cancer subtypes (Table 3). Furthermore, $\mathrm{N} 3$ status was also associated with a poor prognosis (14.78; 95\% CI 1.86 to 117.2). Age and number of positive nodes remain independent factors for unfavorable outcome as were in the untreated group. 
Table 1 Age and clinicopathologic variables at diagnosis by breast cancer subtype in untreated patients

\begin{tabular}{|c|c|c|c|c|c|c|}
\hline Variable/subtype & $\begin{array}{l}\text { Total }(n=301) \\
\text { No. }(\%)\end{array}$ & $\begin{array}{l}\mathrm{HR}^{+} / \mathrm{HER} 2^{-}(n=224) \\
\text { No. }(\%)\end{array}$ & $\begin{array}{l}\mathrm{HR}^{+} / \mathrm{HER} 2^{+}(n=21) \\
\text { No. }(\%)\end{array}$ & $\begin{array}{l}\text { TNBC }(n=43) \\
\text { No. }(\%)\end{array}$ & $\begin{array}{l}\text { HER2 }^{+}(n=13) \\
\text { No. }(\%)\end{array}$ & $P$ value* \\
\hline Age at diagnosis & & & & & & 0.047 \\
\hline$\leq 50$ & $61(20.3 \%)$ & $38(17.0 \%)$ & $7(33.3 \%)$ & $14(32.6 \%)$ & $2(15.4 \%)$ & \\
\hline$>50$ & $240(79.7 \%)$ & $186(83.0 \%)$ & $14(66.7 \%)$ & $29(67.4 \%)$ & $11(84.6 \%)$ & \\
\hline Histology & & & & & & 0.344 \\
\hline Ductal & $267(88.7 \%)$ & $195(87.1 \%)$ & $20(95.2 \%)$ & $39(90.7 \%)$ & $13(100 \%)$ & \\
\hline Lobular & $34(11.3 \%)$ & $29(12.9 \%)$ & $1(4.76 \%)$ & $4(9.3 \%)$ & $0(0 \%)$ & \\
\hline T stage & & & & & & 0.793 \\
\hline $\mathrm{T} 1$ & $226(75.1 \%)$ & $172(76.8 \%)$ & $17(81 \%)$ & $29(67.4 \%)$ & $8(61.5 \%)$ & \\
\hline $\mathrm{T} 2$ & $52(17.3 \%)$ & $37(16.5 \%)$ & $3(14.3 \%)$ & $9(20.9 \%)$ & $3(23.1 \%)$ & \\
\hline $\mathrm{T} 3$ & $16(5.32 \%)$ & $10(4.46 \%)$ & $1(4.76 \%)$ & $4(9.3 \%)$ & $1(7.69 \%)$ & \\
\hline $\mathrm{T} 4$ & $7(2.33 \%)$ & $5(2.23 \%)$ & $0(0 \%)$ & $1(2.33 \%)$ & $1(7.69 \%)$ & \\
\hline $\mathrm{N}$ stage & & & & & & 0.076 \\
\hline No & $241(80.1 \%)$ & $186(83 \%)$ & $15(71.4 \%)$ & $33(76.7 \%)$ & $7(53.8 \%)$ & \\
\hline N1 & $55(18.3 \%)$ & $34(15.2 \%)$ & $5(23.8 \%)$ & $10(23.3 \%)$ & $6(46.2 \%)$ & \\
\hline $\mathrm{N} 2$ & $5(1.66 \%)$ & $4(1.79 \%)$ & $1(4.76 \%)$ & $0(0 \%)$ & $0(0 \%)$ & \\
\hline Tumor size & & & & & & 0.378 \\
\hline$\leq 2$ & $226(75.1 \%)$ & $172(76.8 \%)$ & $17(81.0 \%)$ & $29(67.4 \%)$ & $8(61.5 \%)$ & \\
\hline $2-5$ & $57(18.9 \%)$ & $42(18.8 \%)$ & $3(14.3 \%)$ & $9(20.9 \%)$ & $3(23.1 \%)$ & \\
\hline$>5$ & $18(5.98 \%)$ & $10(4.46 \%)$ & $1(4.76 \%)$ & $5(11.6 \%)$ & $2(15.4 \%)$ & \\
\hline $\mathrm{N}$ of positive nodes & & & & & & 0.025 \\
\hline 0 & $241(80.1 \%)$ & $186(83.0 \%)$ & $15(71.4 \%)$ & $33(76.7 \%)$ & $7(53.8 \%)$ & \\
\hline $1-3$ & $39(13.0 \%)$ & $25(11.2 \%)$ & $3(14.3 \%)$ & $7(16.3 \%)$ & $4(30.8 \%)$ & \\
\hline $4-9$ & $10(3.3 \%)$ & $4(1.8 \%)$ & $1(4.8 \%)$ & $3(7.0 \%)$ & $2(15.4 \%)$ & \\
\hline$\geq 10$ & $11(3.7 \%)$ & $9(4.0 \%)$ & $2(9.5 \%)$ & $0(0 \%)$ & $0(0 \%)$ & \\
\hline Tumor grade & & & & & & $<0.001$ \\
\hline I & $92(30.6 \%)$ & $86(38.4 \%)$ & $5(23.8 \%)$ & $1(2.33 \%)$ & $0(0 \%)$ & \\
\hline II & $136(45.2 \%)$ & $109(48.7 \%)$ & $10(47.6 \%)$ & $13(30.2 \%)$ & $4(30.8 \%)$ & \\
\hline III & $73(24.3 \%)$ & $29(12.9 \%)$ & $6(28.6 \%)$ & $29(67.4 \%)$ & $9(69.2 \%)$ & \\
\hline Stage & & & & & & 0.361 \\
\hline I & $197(65.4 \%)$ & $153(68.3 \%)$ & $14(66.7 \%)$ & $25(58.1 \%)$ & $5(38.5 \%)$ & \\
\hline II & $80(26.6 \%)$ & $56(25 \%)$ & $5(23.8 \%)$ & $13(30.2 \%)$ & $6(46.2 \%)$ & \\
\hline III & $24(7.97 \%)$ & $15(6.7 \%)$ & $2(9.52 \%)$ & $5(11.6 \%)$ & $2(15.4 \%)$ & \\
\hline ER status & & & & & & $<0.001$ \\
\hline Negative & $71(23.6 \%)$ & $15(6.7 \%)$ & $0(0 \%)$ & $43(100 \%)$ & $13(100 \%)$ & \\
\hline Positive & $230(76.4 \%)$ & $209(93.3 \%)$ & $21(100 \%)$ & $0(0 \%)$ & $0(0 \%)$ & \\
\hline PR status & & & & & & $<0.001$ \\
\hline Negative & $90(29.9 \%)$ & $28(12.5 \%)$ & $6(28.6 \%)$ & $43(100 \%)$ & $13(100 \%)$ & \\
\hline Positive & $211(70.1 \%)$ & $196(87.5 \%)$ & $15(71.4 \%)$ & $0(0 \%)$ & $0(0 \%)$ & \\
\hline HER2 status & & & & & & $<0.001$ \\
\hline Negative & $267(88.7 \%)$ & $224(100 \%)$ & $0(0 \%)$ & $43(100 \%)$ & $0(0 \%)$ & \\
\hline Positive & $34(11.3 \%)$ & $0(0 \%)$ & $21(100 \%)$ & $0(0 \%)$ & $13(100 \%)$ & \\
\hline
\end{tabular}

$C I$ confidence interval, $E R$ estrogen receptor, $H E R 2$ human epidermal growth factor receptor 2, $H R$ hazard ratio, $P R$ progesterone receptor, $N o$. number, $O S$ overall survival, TNBC triple-negative breast cancer

$* P<0.05$ was considered statistically significant 
Fig. 1 Overall survival among breast cancer subtypes by treatment status. Kaplan-Meier analysis of the survival in the absence of treatment among $\mathrm{HR}^{+} / \mathrm{HER} 2^{-}, \mathrm{HR}^{+} / \mathrm{HER}^{+}{ }^{+}$, TNBC, and HER $2^{+}$subtypes (a); and the survival rates in patients with $\mathrm{HR}^{+} / \mathrm{HER} 2^{-}$, $\mathrm{HR}^{+} / \mathrm{HER} 2^{+}, \mathrm{TNBC}$, and HER $2^{+}$subtypes undergoing conventional therapy (b). $\mathrm{HR}^{+} /$ HER $2^{-}$, hormone receptor-positive and HER2-negative; $\mathrm{HR}^{+} /$ HER $2^{+}$, hormone receptor-positive and HER2-positive; TNBC, triple-negative breast cancer

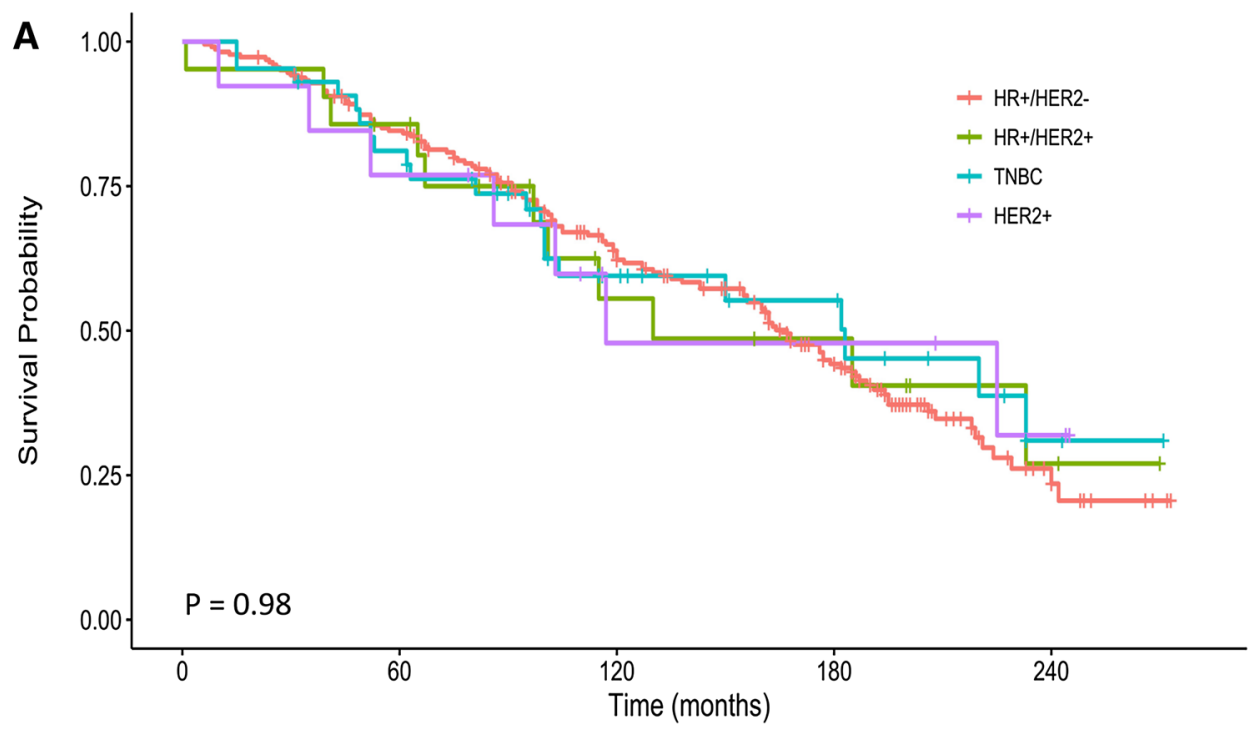

Number at risk
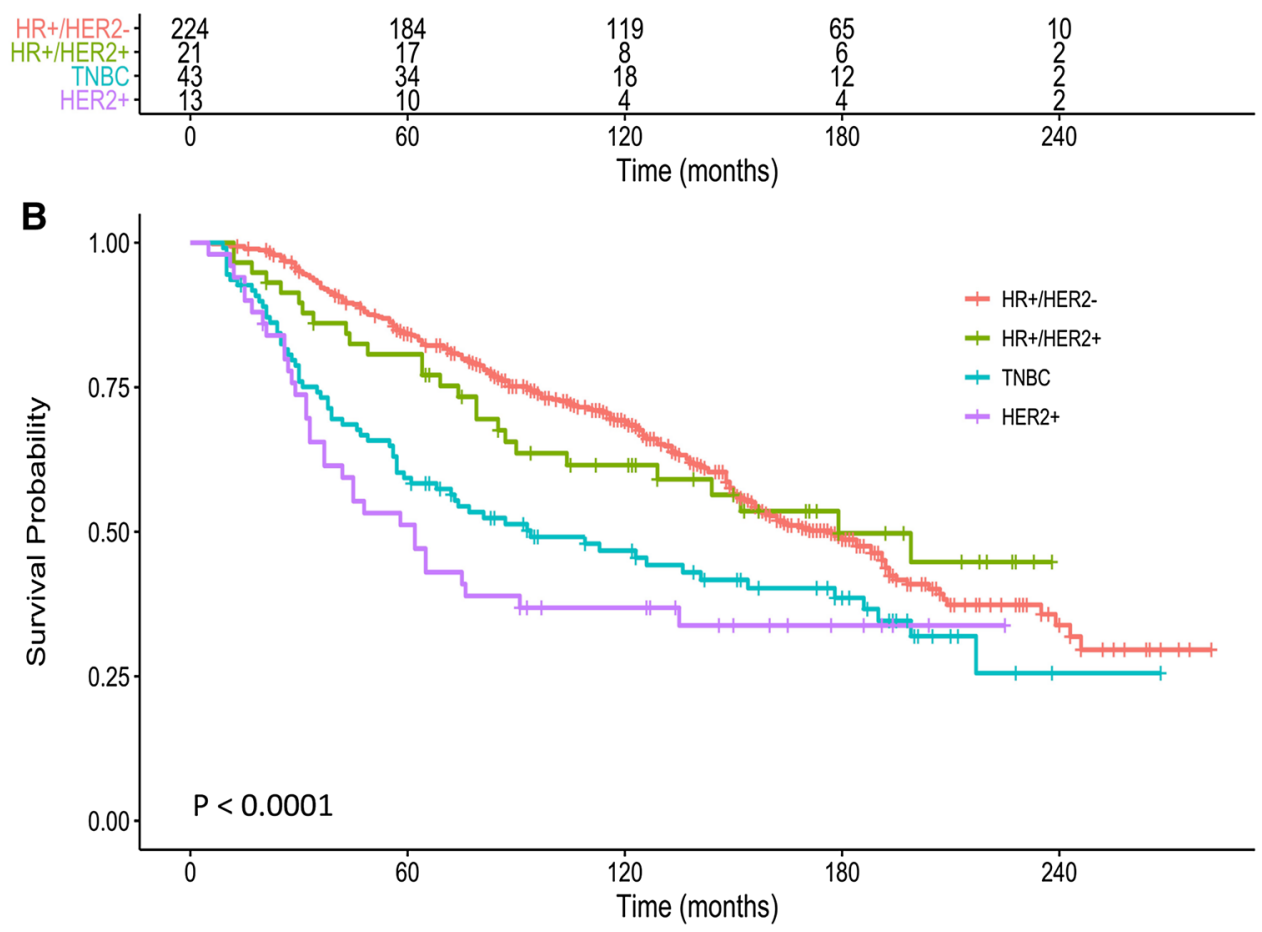

Number at risk

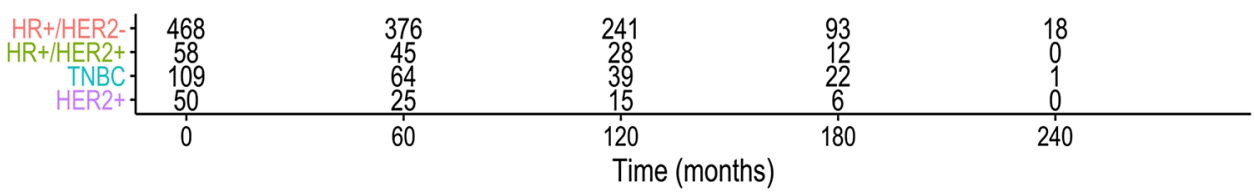

\section{Discussion}

Molecular subtypes of breast cancer are extensively investigated surrounding the biological heterogeneity of breast tumors and prognostic relevance in the context of conventional care of management [27]. However, its prognostic value has not been assessed in patients without any type of treatments including systemic and radiation therapy as an independent group. The subtype datasets of "the no systemic therapy" used in several previous studies had included breast tumor samples from patients with 
Table 2 Multivariable Cox's regression analyses for OS in 301 untreated patients

\begin{tabular}{llll}
\hline Variable & Adjusted HR & $95 \%$ CI & $P$ value* \\
\hline HR $^{+} / \mathrm{HER}^{+}$ & 1.1 & $(0.55-2.07)$ & 0.84 \\
TNBC $^{+}$ & 0.68 & $(0.40-1.18)$ & 0.17 \\
HER2 $^{+}$ & 0.69 & $(0.29-1.58)$ & 0.37 \\
Age at diagnosis $>50$ & 2.22 & $(1.35-3.64)$ & 0.0017 \\
Histology lobular & 1.36 & $(0.84-2.20)$ & 0.21 \\
T Stage & & & \\
T2 & 1.71 & $(0.73-3.98)$ & 0.21 \\
T3 & 0.36 & $(0.06-1.98)$ & 0.24 \\
T4 & 1.31 & $(0.17-9.73)$ & 0.79 \\
N Stage & & & \\
$\quad$ N1 & 1.34 & $(0.64-2.81)$ & 0.44 \\
N2 & 0.5 & $(0.07-3.69)$ & 0.5 \\
Invasive tumor size & 1.15 & $(0.93-1.43)$ & 0.2 \\
Number of positive nodes & 1.11 & $(1.04-1.18)$ & 0.0008 \\
Grade II & 1.07 & $(0.73-1.59)$ & 0.72 \\
Grade III & 1.38 & $(0.82-2.32)$ & 0.23 \\
Stage II & 0.84 & $(0.35-1.93)$ & 0.66 \\
Stage III & 3.64 & $(0.48-27.45)$ & 0.21 \\
\hline
\end{tabular}

$C I$ confidence interval, $H R$ hazard ratio, $O S$ overall survival, $T N B C$ triple-negative breast cancer

${ }^{*} \mathrm{HR}^{+} / \mathrm{HER} 2^{-}$subtype used as reference for comparison with other three subtypes. $P<0.05$ was considered statistically significant

Table 3 Multivariable Cox's regression analyses for OS in 685 patients with treatments

\begin{tabular}{lccc}
\hline Variable & Adjusted HR & $95 \%$ CI & $P$ value* \\
\hline HR $^{+} / \mathrm{HER}^{+}$ & 0.96 & $(0.63-1.47)$ & 0.84 \\
$\mathrm{TNBC}^{+}$ & 1.5 & $(1.11-2.04)$ & 0.0091 \\
$\mathrm{HER}^{+}$ & 2.18 & $(1.46-3.28)$ & 0.0001 \\
Age at diagnosis $>50$ & 1.94 & $(1.49-2.53)$ & $<0.0001$ \\
Histology lobular & 0.77 & $(0.51-1.18)$ & 0.24 \\
T Stage & & & \\
T2 & 1.25 & $(0.85-1.86)$ & 0.26 \\
T3 & 1.7 & $(0.71-4.10)$ & 0.24 \\
T4 & 1.86 & $(0.83-4.12)$ & 0.13 \\
N Stage & & & \\
N1 & 1.29 & $(0.88-1.90)$ & 0.2 \\
N2 & 1.86 & $(0.94-3.69)$ & 0.07 \\
N3 & 14.78 & $(1.86-117.2)$ & 0.01 \\
Invasive tumor size & 1.1 & $(0.996-1.22)$ & 0.059 \\
Number of positive nodes & 1.02 & $(1.006-1.026)$ & 0.0016 \\
Grade II & 1.27 & $(0.93-1.73)$ & 0.14 \\
Grade III & 1.4 & $(0.99-1.98)$ & 0.057 \\
Stage II & 1.02 & $(0.61-1.72)$ & 0.94 \\
Stage III & 0.92 & $(0.38-2.21)$ & 0.85 \\
\hline
\end{tabular}

$* \mathrm{HR}^{+} / \mathrm{HER} 2^{-}$subtype used as reference for comparison with other 3 subtypes. $P<0.05$ was considered statistically significant

$C I$ confidence interval, $H R$ hazard ratio, $O S$ overall survival, TNBC triple-negative breast cancer radiotherapy, indicative of heterogeneous treatment status [28-30]. For example, a-76 gene signature in node-negative breast cancer was derived from the samples from which $87 \%$ of patients received radiotherapy. Mounting evidence indicates that radiotherapy may have systemic effect in addition to its locoregional management [31]. In the participants represented by the CBCTR network, about one-third of patients did not receive systemic treatments nor radiation therapy. Such dataset allows us to assess the biomarkers for bona fide prognosis. The estimate by both Kaplan-Meier and multivariable analyses adjusting for patient and clinicopathologic factors did not detect any significant survival difference among subtypes in untreated patients. van de Vijver et al. had discussed a 70-gene prognosis signature could not predict metastasis-free survival and OS of untreated nodepositive patients [20]. Of 97 sporadic breast cancer patient samples that were used to develop the 70-gene prognosis signature, 62 patients received radiation therapy, three received chemotherapy and two with hormonal therapy, which indicated a heterogeneous treatment status [21]. Together, these data are important regarding their potential broad implication in understanding the interplay between treatment outcome and biology of breast cancer subtypes and may have implications in other cancer types [32].

Our results show that patients with $\mathrm{HR}^{+}$subtypes had better outcome with conventional therapy, corroborating with large amount of data in the literature [13, 15, 27, 33]. In the meta-analyses conducted by the Early Breast Cancer Trialists' Collaborative Group (Oxford Overview), patients with $\mathrm{ER}^{+}$disease significantly benefited from adjuvant endocrine therapy with tamoxifen as well as polychemotherapy with either CMF (cyclophosphamide, methotrexate, and 5-fluorouracil) regimen or anthracycline/taxane-based regimens [3, 34]. In addition, by the Oxford Overview, a greater benefit from radiotherapy was observed in the $\mathrm{ER}^{+}$group $[35,36]$. A recent systemic review and meta-analysis in a total of 3798 patients demonstrated that the rate of local-regional control is higher in patients with luminal A subtype than in HER 2+ or TNBC patients who received breast conservation therapy followed by radiotherapy [37]. Therefore, $\mathrm{HR}^{+}$ or $\mathrm{HR}^{+} / \mathrm{HER} 2^{-}$tumors are not only sensitive to endocrine therapy but also to radiotherapy and chemotherapy. It is the established therapies lasting about 5 years that had led to the better clinical outcome in patients with $\mathrm{HR}^{+}$and/or $\mathrm{HR}^{+}$/ HER2 $^{-}$disease. Despite these, the risk of breast cancer mortality persists throughout 24 years after primary treatment of $\mathrm{ER}^{+}$breast cancer by a large dataset analysis of clinical trial patients, consistent with our results [38]. Of note, there is no data to directly compare the endocrine therapy alone and chemotherapy alone in HR+early stage breast cancer since endocrine therapy is given upfront due to its low toxicity and effectiveness. In the context of combination of endocrine treatment and chemotherapy, little (additional) benefit 
was observed from endochemotherapy compared with endocrine therapy alone in women with low and intermediate Oncotype recurrence scores [39, 40].

We found substantial drops in the survival rates at 5 years in treated relative to untreated women with TNBC and HER2 $^{+}$subtypes (Fig. 1a, b). The worse outcomes within 5 years in basal-like and HER2 ${ }^{+}$subtypes were initially reported in a subgroup of 49 patients with locally advanced tumors and no distant metastases who were treated with neoadjuvant chemotherapy and adjuvant tamoxifen [15]. The subtype phenotype was subsequently confirmed, with variation in significance, by many other studies either with endocrine therapy, chemotherapy or radiotherapy alone, and/or by endochemotherapy, chemoradiotherapy or endochemoradiotherapy [27, 28, 38, 41, 42]. A historic cohort study also showed the outcome difference that was mostly observed within the first 5 years of follow-up among breast cancer subtypes [19]. Further, HER2 ${ }^{+}$and TNBC subtypes were less effectively responded to radiation therapy relative to the luminal subtypes by a recent systemic review and meta-analysis in four clinical breast cancer subtypes, and this phenomenon was observed in other studies as well $[37,43]$. Moreover, despite initial sensitivity to neoadjuvant chemotherapy, patients with basal-like and HER2 ${ }^{+}$ tumors paradoxically had early relapse, and worse overall and distant disease-free survivals [44]. Altogether, these data may have prompted a need for re-examination of treatment approaches for certain breast cancer subtypes such as TNBC. On the other hand, HER2-targeted therapy likely has shifted the outcome of patients with HER2 ${ }^{+}$subtype, which the population-based estimate is ongoing [45].

It has been shown that triple-negative and HER2 ${ }^{+}$primary breast tumors exhibited higher frequency of expression of $\gamma \mathrm{H} 2 \mathrm{AX}$, a component in the ATM/H2AX DNA damage response complex that facilitates the DNA damage repair [23]. The data that constitutive expression of $\gamma \mathrm{H} 2 \mathrm{AX}$ at diagnosis was associated with worse survival in patients who received chemotherapy provided a molecular mechanism of action of resistance [46]. In addition, a large decrease versus minor reduction of $\gamma \mathrm{H} 2 \mathrm{AX}$ was associated with better response to neoadjuvant chemotherapy in TNBC [44].

It is worth to note that the size of this investigation population was relatively small, compared to those of a similar type. Despite the limitation, our research represents a first step, with significance, to address the question of the molecular subtypes of breast cancer for prognosis in patients with and without conventional treatments as distinct entities. Validation of the association between the breast cancer subtypes and treatment outcomes is warranted in other retrospective studies and clinical trials.

\section{Conclusions}

The results through 23.5 years of clinical follow-up provided an evidence of the impact of conventional therapy to the differential survival outcomes in treated versus untreated patients with distinct breast cancer subtypes. In addition, patients in this study represented the general breast cancer population who received their care at community hospitals. Our results, if validated by other studies and clinical trials, may have an implication in prompting the re-examination of treatment modalities such as chemotherapy that currently apply to all TNBC and HER2 ${ }^{+}$patients.

Acknowledgements Supported in part by the Division of Cancer Treatment and Diagnosis of the National Cancer Institute, National Institutes of Health. We would like to thank patients who participated the program, gave their consent and donated their breast cancer specimens to research. We are grateful to the physicians, nurses, pathologists, statisticians and research staff who designed, established, and maintained the database at each participating sites, CBCTR and the Cancer Diagnosis Program at the National Cancer Institute.

Author contributions $\mathrm{SY}$ and EP were involved in the conception and design of the study. The CBCTR and NCI Cancer Diagnosis program assisted with data collection and clinical follow-up. EP and SY assisted with data collection and data analysis. All authors contributed to the writing of the manuscript.

\section{Compliance with ethical standards}

Competing interests The authors declare no conflict of interests.

Ethics approval All study sites had been previously received full review with appropriate ethics approval and consent. The current study on the de-identified human tumor specimen/dataset was approved by the Office of Human Research Protections, National Institutes of Health, Bethesda, Maryland, USA.

Open Access This article is distributed under the terms of the Creative Commons Attribution 4.0 International License (http://creativeco mmons.org/licenses/by/4.0/), which permits unrestricted use, distribution, and reproduction in any medium, provided you give appropriate credit to the original author(s) and the source, provide a link to the Creative Commons license, and indicate if changes were made.

\section{References}

1. WCRF. https://www.wcrf.org/int/cancer-facts-figures/data-speci fic-cancers/breast-cancer-statistics

2. Siegel RL, Miller KD, Jemal A (2018) Cancer statistics, 2018. CA Cancer J Clin 68:7-30

3. Early Breast Cancer Trialists' Collaborative G, Peto R, Davies C, Godwin J, Gray R, Pan HC et al (2012) Comparisons between different polychemotherapy regimens for early breast cancer: metaanalyses of long-term outcome among 100,000 women in 123 randomised trials. Lancet 379:432-444 
4. Pan H, Gray R, Braybrooke J, Davies C, Taylor C, McGale P et al (2017) 20-year risks of breast-cancer recurrence after stopping endocrine therapy at 5 years. N Engl J Med 377:1836-1846

5. McGuire WL (1978) Hormone receptors: their role in predicting prognosis and response to endocrine therapy. Semin Oncol 5:428-433

6. Slamon DJ, Godolphin W, Jones LA, Holt JA, Wong SG, Keith DE et al (1989) Studies of the HER-2/neu proto-oncogene in human breast and ovarian cancer. Science 244:707-712

7. AJCC Cancer Staging Manual, 8 ed. (2017). Springer, New York

8. Gradishar WJ, Anderson BO, Balassanian R, Blair SL, Burstein HJ, Cyr A et al (2016) Invasive Breast Cancer Version 1.2016, NCCN Clinical Practice Guidelines in Oncology. J Natl Compr Cancer Netw 14:324-354

9. Rugo HS, Rumble RB, Burstein HJ (2016) Endocrine therapy for hormone receptor positive metastatic breast cancer: American Society of Clinical Oncology Guideline Summary. J Oncol Pract 12:583-587

10. Yang SX, Davidson NE (2019) Hormone receptors and endocrine therapy in breast cancer. In: Yang SX, Dancey J (eds) Handbook of therapeutic biomarkers in cancer

11. Yang SX, Costantino JP, Kim C, Mamounas EP, Nguyen D, Jeong $\mathrm{JH}$ et al (2010) Akt phosphorylation at Ser473 predicts benefit of paclitaxel chemotherapy in node-positive breast cancer. J Clin Oncol 28:2974-2981

12. Perou CM, Sorlie T, Eisen MB, van de Rijn M, Jeffrey SS, Rees CA et al (2000) Molecular portraits of human breast tumours. Nature 406:747-752

13. Carey LA, Perou CM, Livasy CA, Dressler LG, Cowan D, Conway $\mathrm{K}$ et al (2006) Race, breast cancer subtypes, and survival in the Carolina Breast Cancer Study. JAMA 295:2492-502

14. Brenton JD, Carey LA, Ahmed AA, Caldas C (2005) Molecular classification and molecular forecasting of breast cancer: ready for clinical application? J Clin Oncol 23:7350-7360

15. Sorlie T, Perou CM, Tibshirani R, Aas T, Geisler S, Johnsen H et al (2001) Gene expression patterns of breast carcinomas distinguish tumor subclasses with clinical implications. Proc Natl Acad Sci USA 98:10869-10874

16. Chia SK, Bramwell VH, Tu D, Shepherd LE, Jiang S, Vickery T et al (2012) A 50-gene intrinsic subtype classifier for prognosis and prediction of benefit from adjuvant tamoxifen. Clin Cancer Res 18:4465-4472

17. Goldhirsch A, Wood WC, Coates AS, Gelber RD, Thurlimann B, Senn HJ et al (2011) Strategies for subtypes-dealing with the diversity of breast cancer: highlights of the St. Gallen International Expert Consensus on the Primary Therapy of Early Breast Cancer 2011. Ann Oncol 22:1736-1747

18. Pogue-Geile KL, Song N, Jeong JH, Gavin PG, Kim SR, Blackmon NL et al (2015) Intrinsic subtypes, PIK3CA mutation, and the degree of benefit from adjuvant trastuzumab in the NSABP B-31 trial. J Clin Oncol 33:1340-1347

19. Engstrom MJ, Opdahl S, Hagen AI, Romundstad PR, Akslen LA, Haugen OA et al (2013) Molecular subtypes, histopathological grade and survival in a historic cohort of breast cancer patients. Breast Cancer Res Treat 140:463-473

20. van de Vijver MJ, He YD, van't Veer LJ, Dai H, Hart AA, Voskuil DW et al (2002) A gene-expression signature as a predictor of survival in breast cancer. N Engl J Med 347:1999-2009

21. van 't Veer LJ, Dai H, van de Vijver MJ, He YD, Hart AA, Mao $\mathrm{M}$ et al (2002) Gene expression profiling predicts clinical outcome of breast cancer. Nature 415:530-536

22. Glass AG, Donis-Keller H, Mies C, Russo J, Zehnbauer B, Taube $S$ et al (2001) The Cooperative Breast Cancer Tissue Resource: archival tissue for the investigation of tumor markers. Clin Cancer Res 7:1843-1849
23. Yang SX, Polley EC, Nguyen D (2017) Association of gamma$\mathrm{H} 2 \mathrm{AX}$ at diagnosis with chemotherapy outcome in patients with breast cancer. Theranostics 7:945-951

24. Hammond ME, Hayes DF, Dowsett M, Allred DC, Hagerty KL, Badve $S$ et al (2010) American Society of Clinical Oncology/ College Of American Pathologists guideline recommendations for immunohistochemical testing of estrogen and progesterone receptors in breast cancer. J Clin Oncol 28:2784-2795

25. Wolff AC, Hammond MEH, Allison KH, Harvey BE, Mangu PB, Bartlett JMS et al (2018) Human epidermal growth factor receptor 2 testing in breast cancer: American Society of Clinical Oncology/College of American Pathologists clinical practice guideline focused update. J Clin Oncol 36:2105-2122

26. McShane LM, Altman DG, Sauerbrei W, Taube SE, Gion M, Clark GM et al (2006) REporting recommendations for tumor MARKer prognostic studies (REMARK). Breast Cancer Res Treat 100:229-235

27. Prat A, Pineda E, Adamo B, Galvan P, Fernandez A, Gaba L et al (2015) Clinical implications of the intrinsic molecular subtypes of breast cancer. Breast 24(Suppl 2):S26-S35

28. Wang Y, Klijn JG, Zhang Y, Sieuwerts AM, Look MP, Yang F et al (2005) Gene-expression profiles to predict distant metastasis of lymph-node-negative primary breast cancer. Lancet 365:671-679

29. Loi S, Haibe-Kains B, Desmedt C, Lallemand F, Tutt AM, Gillet C et al (2007) Definition of clinically distinct molecular subtypes in estrogen receptor-positive breast carcinomas through genomic grade. J Clin Oncol 25:1239-1246

30. Parker JS, Mullins M, Cheang MC, Leung S, Voduc D, Vickery $\mathrm{T}$ et al (2009) Supervised risk predictor of breast cancer based on intrinsic subtypes. J Clin Oncol 27:1160-1167

31. Formenti SC, Demaria S (2009) Systemic effects of local radiotherapy. Lancet Oncol 10:718-726

32. Yang SX, Polley E, Lipkowitz S (2016) New insights on PI3K/ AKT pathway alterations and clinical outcomes in breast cancer. Cancer Treat Rev 45:87-96

33. Nielsen TO, Parker JS, Leung S, Voduc D, Ebbert M, Vickery T et al (2010) A comparison of PAM50 intrinsic subtyping with immunohistochemistry and clinical prognostic factors in tamoxifen-treated estrogen receptor-positive breast cancer. Clin Cancer Res 16:5222-5232

34. Early Breast Cancer Trialists' Collaborative G, Davies C, Godwin J, Gray R, Clarke M, Cutter D et al (2011) Relevance of breast cancer hormone receptors and other factors to the efficacy of adjuvant tamoxifen: patient-level meta-analysis of randomised trials. Lancet 378:771-784

35. Early Breast Cancer Trialists' Collaborative G, Darby S, McGale P, Correa C, Taylor C, Arriagada R et al (2011) Effect of radiotherapy after breast-conserving surgery on 10 -year recurrence and 15-year breast cancer death: meta-analysis of individual patient data for 10,801 women in 17 randomised trials. Lancet 378:1707-1716

36. Sjostrom M, Lundstedt D, Hartman L, Holmberg E, Killander F, Kovacs A et al (2017) Response to radiotherapy after breast-conserving surgery in different breast cancer subtypes in the swedish breast cancer group 91 radiotherapy randomized clinical trial. J Clin Oncol 35:3222-3229

37. Pan XB, Chen RJ, Huang ST, Jiang YM, Zhu XD (2017) Systematic review and meta-analysis of the efficacy of breast conservation therapy followed by radiotherapy in four breast cancer subtypes. Oncotarget 8:57414-57420

38. Colleoni M, Sun Z, Price KN, Karlsson P, Forbes JF, Thurlimann $B$ et al (2016) Annual hazard rates of recurrence for breast cancer during 24 years of follow-up: results from the international breast cancer study group trials I to V. J Clin Oncol 34:927-935 
39. Paik S, Tang G, Shak S, Kim C, Baker J, Kim W et al (2006) Gene expression and benefit of chemotherapy in women with nodenegative, estrogen receptor-positive breast cancer. J Clin Oncol 24:3726-3734

40. Sparano JA, Gray RJ, Makower DF, Pritchard KI, Albain KS, Hayes DF et al (2018) Adjuvant chemotherapy guided by a 21 -gene expression assay in breast cancer. N Engl J Med 379:111-121

41. Dowsett M, Sestak I, Lopez-Knowles E, Sidhu K, Dunbier AK, Cowens JW et al (2013) Comparison of PAM50 risk of recurrence score with oncotype DX and IHC4 for predicting risk of distant recurrence after endocrine therapy. J Clin Oncol 31:2783-2790

42. Nguyen PL, Taghian AG, Katz MS, Niemierko A, Abi Raad RF, Boon WL et al (2008) Breast cancer subtype approximated by estrogen receptor, progesterone receptor, and HER-2 is associated with local and distant recurrence after breast-conserving therapy. J Clin Oncol 26:2373-2378

43. Langlands FE, Horgan K, Dodwell DD, Smith L (2013) Breast cancer subtypes: response to radiotherapy and potential radiosensitisation. Br J Radiol 86:20120601
44. Carey LA, Dees EC, Sawyer L, Gatti L, Moore DT, Collichio $F$ et al (2007) The triple negative paradox: primary tumor chemosensitivity of breast cancer subtypes. Clin Cancer Res 13:2329-2334

45. Howlader N, Altekruse SF, Li CI, Chen VW, Clarke CA, Ries LA et al (2014) US incidence of breast cancer subtypes defined by joint hormone receptor and HER2 status. J Natl Cancer Inst 106

46. Gruosso T, Mieulet V, Cardon M, Bourachot B, Kieffer Y, Devun F et al (2016) Chronic oxidative stress promotes H2AX protein degradation and enhances chemosensitivity in breast cancer patients. EMBO Mol Med 8:527-549

Publisher's Note Springer Nature remains neutral with regard to jurisdictional claims in published maps and institutional affiliations. 